\title{
Blindness and Visual Impairment in an Urban West African Population: The Tema Eye Survey
}

\author{
Donald L. Budenz, MD, MPH ${ }^{1}$, Jagadeesh R. Bandi, MD, MPH ${ }^{1}$, Keith Barton, MD, FRCS ${ }^{2}$, \\ Winifred Nolan, MD ${ }^{2,3}$, Leon Herndon, MD $^{4}$, Julia Whiteside-de Vos, MD, MPH ${ }^{5,{ }^{,}}$, Graham \\ Hay-Smith, MRCS(Ed), MRCOphth ${ }^{3}$, Hanna Kim, MD ${ }^{6}$, and James Tielsch, PhD ${ }^{5}$ for the \\ Tema Eye Survey Study Group \\ ${ }^{1}$ Department of Ophthalmology, Bascom Palmer Eye Institute, Miller School of Medicine, \\ University of Miami, Department of Ophthalmology, Miami, FL \\ ${ }^{2}$ National Institute for Health Research Biomedical Research Centre for Ophthalmology, \\ Moorfields Eye Hospital, London, UK \\ ${ }^{3}$ Birmingham and Midland Eye Centre, Birmingham, UK \\ ${ }^{4}$ Duke University Eye Center, Durham, NC \\ 5Johns Hopkins Bloomberg School of Public Health, Baltimore, MD \\ ${ }^{6}$ Stanford University School of Medicine, Palo Alto, CA
}

\begin{abstract}
Objective-To determine the prevalence, etiologies, and risk factors of blindness and visual impairment among persons age 40 years and older residing in an urban West African location.

Design-Population-based cross-sectional study.

Participants-Five thousand six hundred and three participants residing in Tema, Ghana.

Methods-Proportionate random cluster sampling was used to select participants age 40 and over living in the city of Tema. Presenting distance visual acuity was measured at 4 and 1 meters using a reduced Logarithm of the Minimum Angle of Resolution (logMAR) tumbling E chart and then with trial frame based on autorefraction. A screening examination was performed in the field on all participants. Complete clinical examination by an ophthalmologist was performed on participants with best corrected visual acuity $<20 / 40$ or failure of any screening test.
\end{abstract}

\footnotetext{
(C) 2012 American Academy of Ophthalmology, Inc. Published by Elsevier Inc. All rights reserved.

Correspondence to Donald L. Budenz, MD, MPH, Department of Ophthalmology, University of North Carolina, 5151 Bioinformatics CB 7040, Chapel Hill, NC 27599., dbudenz@ med.unc.edu.

* Dr. Whiteside was not affiliated with the Johns Hopkins Bloomberg School of Public Health while conducting study activities in Ghana.

Dr. Budenz is currently affiliated with the Department of Ophthalmology, University of North Carolina at Chapel Hill.

Dr. Kim is currently affiliated with the Department of Ophthalmology, Bascom Palmer Eye Institute, Miller School of Medicine, University of Miami, Miami, FL.

**A list of members of the Tema Eye Survey Study Group is available at http://aaojournal.org. This article contains online-only material. The following should appear online only: Tema Eye Survey Study Group, Table 8 and Table 9.

Financial Disclosure: None

Publisher's Disclaimer: This is a PDF file of an unedited manuscript that has been accepted for publication. As a service to our customers we are providing this early version of the manuscript. The manuscript will undergo copyediting, typesetting, and review of the resulting proof before it is published in its final citable form. Please note that during the production process errors may be discovered which could affect the content, and all legal disclaimers that apply to the journal pertain.
} 
Main Outcome Measures-Age- and gender-specific prevalence, causes, and risk factors for blindness (visual acuity in the better eye of $<20 / 400$, World Health Organization definition) and visual impairment (visual acuity in the better eye of $<20 / 40$ ).

Results-Six thousand eight hundred and six eligible participants were identified of which 5603 (82.3\%) participated in the study. The mean age ( \pm standard deviation) of participants was $52.7 \pm 10.9$. The prevalence of visual impairment was $17.1 \%$ and blindness was $1.2 \%$. After refraction and spectacle correction, the prevalence of visual impairment and blindness decreased to $6.7 \%$ and $0.75 \%$ respectively, suggesting that refractive error is the major correctable etiology of visual impairment and blindness in this population. Of 65 subjects having visual acuity < 20/400, 22 (34\%) were correctable with refraction, 21 to the level of visual impairment, and one to normal. The remaining 43 (66\%) had underlying pathology (19 cataract, 9 glaucoma, 3 nonglaucomatous optic neuropathy, 3 corneal opacities, 3 retinal disease, 5 undetermined) that prevented refractive correction. Increased age was a significant risk factor for blindness and visual impairment.

Conclusions-There is a high prevalence of blindness and visual impairment among those aged $\geq 40$ years in Tema, Ghana, West Africa. Refractive error is a major cause of blindness and visual impairment in this population, followed by cataract, glaucoma, and corneal disease.

\section{INTRODUCTION}

Sub-Saharan Africa bears a disproportionate amount of the world's blindness ${ }^{1,2}$ and the proportion of people blind in this region is increasing at a faster rate than in other parts of the world. ${ }^{1,2}$ Ghana is a country of approximately 24 million people ${ }^{3}$ located in West Africa. It currently is in the middle stages of a demographic transition typical of many developing countries in Africa, from a high birth rate and short life expectancy to a lower birth rate and increased longevity. ${ }^{4}$ Part of this demographic transition is driven by a shift from a primarily rural agrarian society (where high birth rates yield economic rewards) to an urban society (where high birth rates have the opposite effect)..$^{5}$ The percentage of Ghana's population that lives in urban areas has more than doubled in the past 50 years, from $23 \%$ in 1960 to $48 \%$ in 2009.6 Chronic eye diseases such as cataract and glaucoma may represent a greater percentage of disease burden today because of the reduced prevalence of infectious causes of blindness such as trachoma and onchocerciasis from improvements in their prevention and treatment as well as population shifts away from endemic regions, ${ }^{1,7}$ and increased life expectancy in developing West African countries such as Ghana. ${ }^{8}$ In addition, improvements in economic status and urbanization have led to increased obesity ${ }^{9}$ and diabetes mellitus prevalence ${ }^{10}$ in Ghana and other developing African countries and the prevalence of diabetic eye disease and its impact on vision in this population is unknown.

The paucity of country-specific data regarding the prevalence of blindness and visual impairment in Africa led the World Health Organization (WHO) in 2004 to recommend additional study of the prevalence and etiologies of visual impairment in sub-Saharan Africa. ${ }^{1}$ The purpose of this portion of the Tema Eye Survey (TES) was to determine the age-specific prevalence and etiologies of, and factors associated with, blindness and visual impairment in an urban West African population.

\section{METHODS}

\section{Study Population}

Tema is a city of the Greater Accra Region in Ghana, West Africa. Approximately $17.6 \%$ percent of Ghana's population lives in the Greater Accra Region, ${ }^{11,}{ }^{12}$ despite the fact that this is the geographically smallest of Ghana's 10 regions. The 2005 estimated population in the Tema District was 562,291, extrapolated from census data from $2000^{12}$ and known birth 
and death rates. As one of the busiest ports in West Africa, Tema has attracted workers from all over Ghana, making it an ethnically and economically diverse environment for study; for these reasons Tema was chosen for the current survey.

Tema is divided into 20 communities. Five of these communities were selected for study based on their ethnic diversity and lower socioeconomic status. These included: Community 1, Ashiaman Southeast, Ashiaman Southwest, Bethlehem/Kakasunanka, and Tema Newtown. These communities are further divided into polling stations by the Ghanaian government for the purpose of voting and represent distinct geographic areas (analogous to neighborhoods). We used voting rolls, which contained the number (but not names) of voting-age individuals and the name of each polling station, to divide the communities into clusters. With the help of local polling officials (usually a local teacher or government official), the polling stations were mapped in each of the five communities selected. A sample size of 5,600 was calculated using the National Center for Health Statistics (NCHS) standards to specifically determine the prevalence of glaucoma in subjects age 40 or over. The NCHS standard for a reliable prevalence estimate is one that has a Relative Standard Error (RSE) of less than or equal to $30 \% .{ }^{13}$

A random cluster sampling strategy with probability of cluster selection proportionate to size of the community under study was used to obtain a representative sample and avoid bias. Each polling station of more than 350 voting-age adults in each of the five communities was eligible for inclusion. Large polling stations (greater than 600 voting-age adults) were broken down into smaller clusters of $350-600$ voting-age individuals. Population data from the 2000 census for Ghana ${ }^{12}$ indicated that $38 \%$ voting-age individuals are age 40 or over while $62 \%$ are between ages 18 and 39 years. It was estimated that 190 subjects would be of an eligible age per cluster. Polling stations with fewer than 350 votingage adults were excluded because these small areas would be expected to yield too few subjects age 40 and over. The number of clusters selected from each of the five communities varied based on the total estimated eligible population in each community, creating a proportional cluster sampling of the population. All eligible clusters within each community were placed in a random number generator and ordered based on the random number order from lowest to highest. A house-to-house census was conducted in each randomly selected cluster and residents age 40 and over were invited to participate in a screening eye examination (field examination) as part of a study. They were given an appointment card with a specific appointment date and time for the following week and asked to bring their glasses with them.

\section{Field Examination}

Field examinations were conducted in schools or churches within subjects' communities near their homes. After the identity, address, and eligibility of each subject was confirmed, written informed consent was obtained. An extensive health questionnaire was taken orally in the subject's native language. Subjects then underwent a screening examination that included testing of presenting visual acuity using the reduced logMAR (logarithm of the minimum angle of resolution) tumbling E chart ${ }^{13}$ at 4 meters and then at 1 meter if they were unable to see any letters at 4 meters. This vision chart provides a close approximation of Early Treatment Diabetic Retinopathy Study (ETDRS) vision but is designed specifically for countries with low literacy rates. Autorefraction (Humphrey Autorefractor model 599, Carl Zeiss Meditec, Dublin, CA, USA) was then performed if the presenting visual acuity (VA) was $<20 / 40$ and the visual acuity was rechecked with a trial frame correction using the autorefraction results. Frequency Doubling Technology perimetry (FDT, Carl Zeiss Meditec, Dublin, CA, USA), intraocular pressure with Tonopen XL (Reichert Ophthalmic Instruments, Depew, NY), ultrasonic pachymetry (DGH, Exton, PA, USA), flashlight screening for potentially occludable anterior chamber angles, ${ }^{14}$ and dilated optic disc and 
macular photographs using a handheld digital fundus camera (Kowa Genesis D, Kowa Company, Ltd, Tokyo, Japan) were then performed. Neither slit lamp examination nor gonioscopy were performed in the field examination. Presenting visual acuity was defined by the visual acuity obtained in the field with the subject's distance glasses on. The field examinations were performed by study personnel from the Unites States (US) or United Kingdom (UK), local ophthalmic nurses, and local ophthalmic technicians. An intensive three week training period was performed by three of the investigators (DLB, KB, WN) on the correct protocol for obtaining informed consent, data collection, field examinations, and use of equipment prior to the study. During this training period, two separate two-day field examination sessions were performed at a church and a mosque in a nearby community that was not part of the study. Subjects who tested positive on any screening tests were referred back to the clinic for complete ophthalmic examination by study investigators for the purpose of training on clinic procedures and to address the medical reasons for positive tests.

\section{Criteria for Referral to Clinic}

Subjects were referred to clinic for complete examination for the following reasons: Best corrected visual acuity worse than 6/12 (20/40) after spectacle correction based on autorefraction; more than one abnormal spot on the FDT Screening C20-5 program on two tests in either eye; intraocular pressure $221 \mathrm{mmHg}$ on the average of two readings; narrow anterior chamber by flashlight testing by ophthalmic nurse; abnormal optic disc or macular photographs as assessed by the Moorfields Eye Hospital Reading Centre. Subjects who were not able to be tested with the FDT screening mode or in whom photographs were not possible were referred to clinic for complete examination.

\section{Clinic Examination}

Clinic examinations consisted of manifest refraction by a licensed optometrist followed by measurement of best corrected visual acuity (BCVA) using the reduced logMAR tumbling E chart at 4 meters then at 1 meter if the subject was unable to see any letter on the chart at 4 meters. Next, automated static perimetry was performed using the Humphrey Visual Field Analyzer 2 with the 24-2 Swedish Interactive Threshold Algorithm (Carl Zeiss Meditec, Dublin, CA) using the subject's best correction with age-appropriate presbyopic correction. All visual fields were uploaded to a secure study website and evaluated by one of the study investigators (JWdV). An investigator/ophthalmologist then performed a complete dilated ophthalmic examination including Goldmann applanation tonometry, gonioscopy, and fundus examination. Lastly, simultaneous stereoscopic optic disc and macular photographs were performed using the Nidek 3Dx camera (Nidek Co., Ltd., Gamagori, Japan). These were uploaded to a secure study website and evaluated in a masked fashion by the Moorfields Eye Hospital Reading Centre, London, UK. BCVA was defined by the visual acuity in the better eye following manifest refraction by the optometrist in the clinic. Visual data is presented for presenting and best corrected vision at the time of presentation, before any intervention, such as cataract surgery. Subjects with visually significant cataracts were referred to the ophthalmologist at the Tema Christian Eye Center for free cataract surgery and referred back to the study clinic for completion of the dilated examination by a study ophthalmologist and posterior segment photographs. Subjects with closed or occludable anterior chamber angles were referred for free laser or surgical iridotomy by a study investigator and then sent back to the study clinic for completion of the dilated examination and photography. Subjects with glaucoma or other ophthalmic conditions requiring monitoring or treatment were referred to the Tema Christian Eye Center for evaluation and management by a local Ghanaian ophthalmologist. Ophthalmologist investigators were asked to determine the presence or absence of any eye disease(s) and were asked to determine the primary etiology of the visual impairment. 


\section{Definitions of Blindness and Visual Impairment}

This study used the World Health Organization's definitions of visual impairment and blindness ${ }^{16}$ with the addition of a category for Mild Visual Impairment (visual acuity < $20 / 40$ to $220 / 60$ ) as suggested by a recent eye survey in Nigeria ${ }^{17}$ and for comparison with US definitions. ${ }^{18,19}$ Moderate Visual Impairment was used for visual acuity $<20 / 60$ but $\geq$ $20 / 200$. Severe Visual Impairment was used for visual acuity $<20 / 200$ but $\geq 20 / 400$. Any visual impairment was defined as visual acuity $<20 / 40$ but $\geq 20 / 400$. Blindness was reserved for those with visual acuity $<20 / 400$ or visual field constriction to less than $10^{\circ}$ from fixation. Anyone who had vision of $20 / 40$ or better was classified as Normal/Near Normal. Data are presented for presenting visual acuity (distance visual acuity in the better seeing eye with presenting correction prior to autorefraction and without pinhole assistance) and best corrected visual acuity (distance visual acuity in the better seeing eye after manifest refraction by an optometrist with correction in trial frame). The cause of blindness and visual impairment for each subject was based on the World Health Organization recommendation that the primary cause should be the pathology that is most amenable to treatment or prevention.

\section{Statistical Analysis}

Age-specific prevalences of visual impairment and blindness were calculated by taking the number of subjects in a specific age group with blindness or visual impairment divided by the number of individuals who participated in the study in that age group. Factors associated with blindness and visual impairment were calculated using logistic regression and MantelHaenszel procedures. Statistical analysis was performed using PASW 18.0 (IBM Inc.).

\section{Protection of Human Subjects and Informed Consent}

The Ethics Committee of the Ghana Ministry of Health and the individual Institutional Review Boards of each of the investigators who examined participants approved this study. The study was conducted in accordance with protection of human subjects guidelines set forth by the Declaration of Helsinki. All study personnel having contact with subjects were required to complete CITI (Collaborative Institutional Training Initiative) certification prior to obtaining informed consent. Each subject signed a written informed consent form approved by the Ghana Ethics Committee prior to conducting any study-related activity. If the subject did not read or speak English, the national language of Ghana, a translator was provided to explain the study and answer questions. On the specific recommendation of the Ethics Committee of the Ghana Ministry of Health, subjects were paid the equivalent of $\$ 2$ US for their participation in field examinations and the equivalent of \$5 US for their participation in clinic examinations. If subjects were asked to repeat clinic examinations or ancillary testing, an additional \$5 US was provided. Since the field examinations were conducted in the communities where subjects resided, no transportation was provided to field examinations. Transportation to and from the clinic was offered free of charge. Field examinations were conducted from September 2006 through August 2008 and clinic examinations continued through December 2008.

\section{RESULTS}

There were a total of 230 clusters identified for sampling in the five communities. Thirty seven of these were randomly chosen, the number of clusters from each community (and therefore, the number of subjects) proportionate to the estimated number of people age 40 and over residing in each community. The house-to-house census enumerated 6806 eligible subjects of whom 5,603 came for the field examination for a participation rate of $82.3 \%$. The field examination identified 1869 (33.3\%) subjects who failed one or more screening 
examinations. Of these, 1538 came back to the clinic for complete examination by an ophthalmologist for a participation rate at this stage of $82.2 \%$.

The demographic characteristics of subjects in the Tema Eye Survey are shown in Table 1. Although $30 \%$ of subjects were from the Greater Accra region, $70 \%$ were born elsewhere in Ghana; $7.7 \%$ were from outside Ghana, from nearby Mali (40), Togo (37), Nigeria (14), and Cote d'Ivoire (13). Table 2 presents the distribution of subjects enumerated in the census and examined in the field by age and gender. In all age ranges, there were more females enumerated and examined than males and this difference increased with age. There were no differences, however, in the proportion of males and females enumerated vs. examined, demonstrating that our sample was representative of the population of this area.

The prevalence of visual impairment and blindness was higher among older participants (Tables 3 and 4). For the entire group, the prevalence of any visual impairment or blindness in presenting visual acuity was $18.3 \%$ (95\% confidence interval, CI, $17.3 \%-19.3 \%)$. The prevalence of any visual impairment or blindness based on BCVA was $7.4 \%$ (95\% CI 6.8\% $-8.1 \%$ ) indicating that refractive error alone accounted for approximately $60 \%$ of the visual impairment and blindness in this population. The prevalence of blindness, defined as visual acuity $<20 / 400$ in the better eye, was $1.2 \%$ (95\% CI $0.9-1.5 \%)$ on presentation and was reduced to $0.75 \%$ (95\% CI $0.54 \%-1.01 \%$ ) using BCVA.

Of the 331 subjects who were examined in the field but did not report for the clinic examination, $63.8 \%$ had been referred for failure of FDT, $29.1 \%$ for IOP greater than 21 $\mathrm{mmHg}$ in either eye, $18.5 \%$ for vision less than $20 / 40$, and $4.7 \%$ for inability to take fundus photographs (subjects could have been referred for more than one reason, thus the totals are greater than 100\%). Subjects who failed to come to clinic were younger (54 vs. 60 years, $\mathrm{P}<$ $0.001)$, had worse vision $(20 / 60$ vs. $20 / 50, \mathrm{P}<0.001)$, and had slightly lower IOP (18 $\mathrm{mmHg}$ vs. $19 \mathrm{mmHg}, \mathrm{P}<0.001)$ than those who came to clinic. Eight percent more women than men failed to come to the clinic examination $(\mathrm{P}=0.001)$.

Sixty-seven subjects had presenting visual acuity $<20 / 400$ of whom 25 were correctable with refraction so that 21 still had visual impairment and the remaining one had normal VA. The remaining 42 subjects had underlying pathology that was not correctable with refraction: 19 cataract, 9 glaucoma, 3 non-glaucomatous optic neuropathy, 3 corneal opacities, 3 retinal diseases, 5 undetermined (Table 5). There were no definite cases of blindness from diabetes mellitus or age related macular degeneration identified. Two cases of corneal opacification were thought to be secondary to trachoma and were in persons aged 68 and 75.

Factors associated with visual impairment (BCVA $<20 / 40$ but $220 / 400$ ) and blindness (BCVA $<20 / 400$ or visual field of $<10^{\circ}$ ) are shown in Tables 6 and 7 respectively. Older age and widowed marital status were significantly associated with visual impairment in the multivariate analysis while age and a prior history of ocular disease were significantly associated with blindness in the multivariate analysis. Data on socioeconomic status were not available.

Because we were concerned about using seven ophthalmologists to determine the cause of visual impairment and blindness, 29 subjects were examined by all investigators in a masked fashion and the presence and cause of visual impairment or blindness was noted by each. Investigators agreed that there was no ophthalmic diagnosis in 14 of them and agreed on the same diagnoses causing visual impairment or blindness in eight. Among the other seven, there were five patients upon whom the examining ophthalmologists disagreed about a determination of primary open angle glaucoma versus glaucoma suspect, one in which there was a disagreement about whether there was chronic narrow angle glaucoma present, and 
one about which there was a disagreement about traumatic glaucoma. However, these did not affect the presence or absence of visual disability and blindness, just the cause of these conditions in these few subjects.

\section{DISCUSSION}

The Tema Eye Survey is one of only a few population studies of blindness, visual impairment, and eye diseases in West Africa and perhaps the only one that has studied a purely urban population. We found a high prevalence of curable vision loss, due to either uncorrected refractive error or cataract. The percentage of curable visual impairment from refractive error or cataract was $39.2 \%$ and the percentage of curable blindness from these causes was $58.3 \%$. In addition, preventable vision loss from glaucoma was found to be a significant problem in this population.

There are several reasons why it is difficult to directly compare blindness prevalence survey results across studies. First, many different definitions of blindness and visual impairment have been used in the past. Second, studies vary widely in how they achieve best corrected vision. The current study used the WHO definition of blindness as presenting distance visual acuity less than 20/400 and visual impairment of varying degrees from less than 20/60 to 20/400. It also included the category of Mild Visual Impairment ( $<20 / 40$ to $220 / 60$ ) for comparison to a recent study in Nigeria ${ }^{16}$ and to the US definition of visual impairment (< 20/40), ${ }^{17}$ as evidenced by the legal limits for a driver's license in most US states. ${ }^{18,19}$ The current study went to great length to provide best corrected vision in subjects by having them refracted by an optometrist and then retested.

There have been two other population surveys of the prevalence and etiologies of blindness in Ghana. Both were conducted in rural areas. In the early $1990 \mathrm{~s}$, Moll et al ${ }^{20}$ surveyed 866 subjects age 40 and over residing in 10 villages distant from the onchocerciasis endemic area around the Black Volta River. They found a $2.4 \%$ prevalence of blindness (WHO definition, VA $<20 / 400$ in better eye) for people age 40 and over. In this study, nonophthalmologist observers assessed presenting and pinhole visual acuities without refraction, slit lamp examination, dilated fundus examination, or standardized diagnostic criteria for glaucoma. The etiologies of blindness and visual impairment determined by nonophthalmologist observers were cataract (62.5\%), onchocerciasis $(12.5 \%)$ and corneal opacities (8.2\%). More recently, Guzek and colleagues ${ }^{21}$ performed a survey of 2298 subjects age 40 and over in three districts of the rural mid-Volta region of Ghana. Three ophthalmologists and two optometrists performed refractions and complete dilated eye examinations. They found a $2.8 \%$ prevalence of blindness (VA < 20/400) with the main etiologies being cataract $(53.9 \%)$ and glaucoma (20.6\%). These investigators did not comment on corneal blindness and found no definite cases of onchocerciasis and only one case of possible inactive trachoma. We found two cases of suspected inactive trachoma as possible causes of corneal blindness. It is possible that there were cases of inactive onchocerciasis that was misdiagnosed as toxoplasmosis or chorioretinal scarring of indeterminate etiology.

There have been several other population-based surveys of blindness and eye disease in West Africa. In the mid 1980s, Faal et al. ${ }^{22}$ surveyed 8174 people of all ages living in both urban and rural communities in Gambia. They found a $0.7 \%$ prevalence of blindness (VA < 20/400) and a $1.4 \%$ prevalence of visual impairment (VA < 20/60). The age-specific prevalence of blindness and visual impairment in adults age 40 and over were very similar to those in the current study (Table 8, available at http://aaojournal.org). The three most common etiologies of blindness were cataract (55\%), corneal opacity (20\%), and trachoma (17\%). In 1990, Kortlang and colleagues ${ }^{23}$ surveyed 5871 rural residents of all ages residing 
in Mali and found a $1.7 \%$ prevalence of both blindness (VA < 20/400) and visual impairment (VA < 20/60). Only 719 subjects $(12.2 \%)$ were, however, age 50 or over. The most frequent causes of blindness in that study were cataract (69\%), trachoma (23\%) and glaucoma (9\%). In 1993, Whitworth and associates ${ }^{24}$ examined 1625 subjects of all ages residing in six rural villages in Sierra Leone in an area known to be hyperendemic for onchocerciasis. The prevalence of blindness (VA $<20 / 200$ in better eye) in this population was $1.3 \%$ and visual impairment (VA $<20 / 60$ but $>20 / 200$ ) $4.3 \%$. Again, the prevalence of blindness and visual impairment was understandably lower in that study than in ours because of the lower age of the study population. Not surprisingly, onchocerciasis was the leading cause of blindness (48\%), followed by cataracts (19\%), corneal opacity (14.3\%), and glaucoma (9.5\%). In 1996 Wilson et al. ${ }^{25}$ surveyed 10,647 subjects of all ages (2183 age 40 or over) in both rural and urban areas in the northern province of Cameroon. They found a combined prevalence of blindness (VA < 20/200) of 3.7\% for all age groups and $15.9 \%$ for people age 40 or over. The leading causes of blindness in all age groups were cataract (55\%), glaucoma (12\%), refractive error (9.7\%), and trachoma (7.4\%). Most recently, the Nigerian National Blindness and Visual Impairment Survey ${ }^{17}$ studied 13,599 subjects age 40 and over. The strength of that survey was that it sampled both rural and urban communities throughout Nigeria. Using the same definitions for visual impairment and blindness as our study, the authors found a prevalence of blindness (BCVA < 20/400) of $3.4 \%$ and a prevalence of visual impairment (BCVA<20/40) of $14 \%$. Table 8 (available at http://aaojournal.org) summarizes the prevalence of visual impairment and blindness in the current study compared to other prevalence studies performed in Ghana and West Africa.

Table 9 (available at http://aaojournal.org) summarizes the prevalence of blindness and visual impairment from previous studies that reported age-specific data with an emphasis on ethnicity. Comparison with previous studies suggests that people of African descent residing in Africa, the Caribbean, the UK, and the US have higher prevalences of visual impairment and blindness than other ethnic groups with the exception of Indian Asians, although direct comparison of these studies is difficult because of the difference between age-specific and age-adjusted data. Age is the strongest risk factor for eye disease in all epidemiologic studies and the life expectancy in the US, UK, and Caribbean (mid 70s) is approximately twenty years higher than in West Africa (mid 50s). The US, UK, and Caribbean populations, which have a higher percentage surviving to older ages, would thus be expected to have a higher prevalence of eye diseases, blindness, and visual impairment.

This study has several limitations. Firstly, it would have been ideal to have determined the prevalence of visual impairment and blindness in people of all ages. However, the prevalence of eye disease is quite low under age 50 years and the much larger sample size needed to draw any meaningful conclusions from prevalence data in younger age groups would have been financially prohibitive. We chose to study people age 40 and over, rather than 50 and over, to attempt to capture the phenomenon of a younger age of onset of glaucoma previously reported in people of African descent. The prevalence of glaucoma in this population will be elucidated and compared to that in non-Africans in a separate report.

A second limitation of this study is that we did not collect data on the prevalence of blindness and visual impairment in rural Ghana so we cannot generalize the results of the Tema Eye Survey to the entire country. However, the first population survey of eye disease, the Baltimore Eye Survey, ${ }^{26}$ studied only urban-dwelling blacks and whites and these data have been used to generalize to urban and rural black and white Americans for two decades. In addition, there have been two population based surveys in rural Ghana ${ }^{20,21}$ and several in rural Africa. ${ }^{17,22-25}$ Thirdly, because $50 \%$ of Ghanaians currently live in urban areas and increasing urbanization is projected, it made sense to collect blindness and disease prevalence estimates from an urban setting. Surveying only rural subjects, as done 
previously, may overestimate the prevalence of blindness and visual impairment due to the high rates of infectious diseases such as trachoma and onchocerciasis and underestimate the prevalence of chronic diseases such as cataract and glaucoma. We realize that the opposite phenomenon is a limitation of the current study; namely, that surveying only urban Ghanaians results in a lower prevalence estimate of trachoma and onchocerciasis. The Nigerian National survey data ${ }^{17}$ show the unadjusted blindness prevalence for urban and rural areas to be $3.8 \%$ [95\% CI 3.1-4.7\%] and 4.5\% [95\% CI 3.8-4.8\%] $(\mathrm{p}=0.18)$ respectively. However, after adjusting for age and sex the relative risk was 1.0.

We considered performing the current survey in 5 or 6 different urban and rural regions of Ghana and determined that this was not feasible for budgetary and logistical reasons. The Tema district was chosen partly because of its ethnic diversity. The study population was quite diverse in that most of the subjects were born in regions outside of the study area. We recognize, however, that the results may not be generalizable to the rest of Ghana or all of West Africa, because African populations may be the most genetically diverse in the world. ${ }^{38-40}$ Also, environmental factors, as well as gene-environment interactions, may affect the phenotypic expression of complex diseases such as glaucoma. ${ }^{38-40}$ On the other hand, recent genetic studies suggest that at least three prominent West African populations demonstrate striking "genetic homogeneity". $41-45$ These West African ethnic groups are part of the linguistically similar Niger-Kordofanian "macrofamily", which covers more of Africa than any other ethno-linguistic macrofamily and is believed to have expanded to the west from the current border area of Niger and Cameroon and then to central and southern Africa. $38,46,47$ So perhaps generalization of genetically determined eye diseases such as glaucoma is possible from this study.

A third practical limitation of the current study is that participants were examined by seven different ophthalmologists rather than by the same ophthalmologist. The ophthalmologists examining subjects undoubtedly had different diagnostic criteria and might have been biased towards the disease of their subspecialty. Most of the investigators were comprehensive ophthalmologists or glaucoma specialists with many years of experience diagnosing anterior segment, optic nerve and retinal diseases. In addition, most diagnoses, like glaucoma and retinal diseases, were made based solely on visual fields read by a masked glaucoma specialist and fundus photographs read by masked readers. Other diagnoses, such as corneal opacification and cataract, are so obvious that we doubt this influenced the results of the study. Thus we do not believe this to be much of a limitation. Furthermore using multiple examiners seemed to be the best approach because of the impracticality of a single ophthalmologist examining all 5,600 subjects over 2 years and 4 months.

As with virtually all similar population surveys, the Tema Eye Survey had more female than male participants. There may be several reasons for this. First, more females are available during weekdays to participate, particularly in developing countries where fewer women work outside the home. Second, the life expectancy is longer in women than men and, since most eye surveys study people age 40 and older, it is not surprising that one finds more female than male participants. In the oldest age group ( $\geq 80)$, for instance, there were 129 women enumerated compared to only 53 men. This simply reflects the earlier age of death of men compared to women. In addition, the 2010 Ghana census showed that there are $48.7 \%$ males compared to $51.3 \%$ females of all ages.

The current study chose to sample subjects in poor areas of Tema. This was done to increase participation rates, as people with middle to upper class incomes typically do not participate since they have the means and access to good eye care. The effect of this is that most surveys, like the current one, probably overestimate the prevalence of visual impairment and 
blindness from curable conditions like cataract and preventable blindness from diseases such as glaucoma.

The current study has implications for preventable visual impairment and blindness in Ghana and similar developing countries in Sub-Saharan Africa. Firstly, refractive error represented a significant cause of needless visual impairment in this low income population. In this study, the prevalence of visual impairment and blindness was reduced from $18.3 \%$ to 7.4\% with manifest refraction alone. We recognize the fact that these data are based on presenting visual acuity, which assumes subjects brought their glasses to the field examination place as instructed. However, one would think that subjects with significant visual impairment who owned glasses would have worn them on a regular basis, including walking to our field examination location from their homes. The WHO Vision 2020: Right to Sight report ${ }^{48}$ has made the correction of refractive error a priority in their Global Initiative for the Elimination of Avoidable Blindness because it is so cost effective. The results of the current study support the need for initiatives to increase the examination rate and provision of glasses in countries like Ghana.

The second important public health implication of this study is that much of the visual impairment and blindness in this population is due to chronic, rather than infectious, eye diseases, primarily cataract and glaucoma. This finding is consistent with the most recent WHO meta-analysis of causes of blindness and visual impairment worldwide conducted in 2002. ${ }^{1}$ An updated analysis is due to be published shortly (Rupert Bourne, personal communication). The current study of 5,600 Africans did not identify any definite cases of onchocerciasis and found very few cases of trachoma, a legacy of the successful intervention programs for these disorders conducted over the past 20 years. ${ }^{7}$ While ongoing efforts are still needed in these areas, they do not help the $50 \%$ or so of people residing in urban areas of sub-Saharan Africa who have non-infectious eye diseases. With increased urbanization of this region and improved longevity, developing countries in Africa must recognize the importance of chronic eye diseases of the elderly, such as cataract and glaucoma. This is quite different from the causes of blindness and visual impairment found in Caucasian populations of developed country, where age0-related macular degeneration and diabetic retinopathy contribute significantly to the burden of blindness. In addition, the current study argues for renewed focus on the prevention of avoidable blindness in urban populations by increasing the number of ophthalmologists and improving access to ophthalmic care. Ghana, for instance, currently has approximately 40 ophthalmologists to care for its 24 million people, a ratio of approximately one ophthalmologist for every 600,000 people. This compares with a ratio of at least one ophthalmologist for every 10,000 inhabitants in the $\mathrm{US}^{49}$ and one for every 41,000 in the UK, ${ }^{50}$ which has the lowest number of ophthalmologists per person of any European country. ${ }^{50}$ Ministries of health should be encouraged to direct resources to prevent or cure visual impairment and blindness with increased rates of general ophthalmic care and cataract surgery, including earlier diagnosis and appropriate management of glaucoma.

\section{Supplementary Material}

Refer to Web version on PubMed Central for supplementary material.

\section{Acknowledgments}

Grant Info: Supported by grants to International Aid, Spring Lake, MI, from Pfizer, Inc., the Allergan Foundation, Mid-Career Physician Scientist Award from the American Glaucoma Society (Dr. Budenz), National Institutes of Health, National Eye Institute Training Grant Number EY 07127, Clinical Trials Training Program in Vision Research (Dr. Whiteside). 
The authors would like to thank Mr. Pak Sang Lee of the NIHR Biomedical Research Centre for Ophthalmology, UCL Institute of Ophthalmology, and Moorfields Eye Hospital, London, England who provided technical training and support on this study.

\section{References}

1. Thylefors B, Négrel AD, Pararajasegaram R, Dadzie KY. Global data on blindness. Bull World Health Organ. 1995; 73:115-21. [PubMed: 7704921]

2. Resnikoff S, Pascolini D, Etya'ale D, et al. Global data on visual impairment in the year 2002. Bull World Health Organ. 2004; 82:844-51. [PubMed: 15640920]

3. Ghana Statistical Service. [Accessed on April 5, 2012] Ghana Provisional Census Results. 2010. Available at: http://www.ghana.gov.gh/census/phc2010.pdf

4. Caldwell JC, Caldwell P. The cultural context of high fertility in sub-Saharan Africa. Popul Dev Rev. 1987; 13:409-37.

5. Caldwell JC. Demographic theory: a long view. Popul Dev Rev. 2004; 30:297-316.

6. World Bank. [Accessed April 5, 2012] Ghana at a Glance. Updated February 2011. Available at: http://devdata.worldbank.org/AAG/gha_aag.pdf

7. Schwab, L. Eye Care in Developing Nations. 4. London: Manson; 2007. p. 117-143.

8. Ghana Statistical Service. Ghana Demographic and Health Survey 2008. Calverton, MD: ICF Macro; 2009. p. 3

9. Biritwum RB, Gyapong J, Mensah G. The epidemiology of obesity in Ghana. Ghana Med J. 2005; 39:82-5. [PubMed: 17299549]

10. Amoah AG, Owusu SK, Adjei S. Diabetes in Ghana: a community based prevalence study in Greater Accra. Diabetes Res Clin Pract. 2002; 56:197-205. [PubMed: 11947967]

11. Ghana Statistical Service. [Accessed August 1, 2010] Greater Accra Region. Available at: http:// www.statsghana.gov.gh/greater_accra.html

12. Ghana Statistical Service. [Accessed April 5, 2012] Ghana-Population and Housing Census 2000 [database online]. Accra. Available at: http://www.statsghana.gov.gh/nada/index.php/ddibrowser/3

13. Klein, RJ.; Proctor, SE.; Boudreault, MA.; Turczyn, KM. [Accessed April 5, 2012] Healthy People 2010 criteria for data suppression; Healthy People 2010 Stat Notes. 2002. p. 1-12.Available at: http://www.cdc.gov/nchs/data/statnt/statnt24.pdf

14. Bourne RR, Rosser DA, Sukudom P, et al. Evaluating a new logMAR chart designed to improve visual acuity assessment in population-based surveys. Eye (Lond). 2003; 17:754-8. [PubMed: 12928690]

15. Patel KH, Javitt JC, Tielsch JM, et al. Incidence of acute angle-closure glaucoma after pharmacologic mydriasis. Am J Ophthalmol. 1995; 120:709-17. [PubMed: 8540544]

16. World Health Organization. [Accessed August 1, 2010] ICD Update and Revision Platform: Change the Definition of Blindness. Available at: http://www.who.int/blindness/Change\%20the $\%$ 20Definition\%20of\%20Blindness.pdf

17. Kyari F, Gudlavalleti MVS, Sivsubramaniam S, et al. Nigeria National Blindness and Visual Impairment Study Group. Prevalence of blindness and visual impairment in Nigeria: the National Blindness and Visual Impairment Survey. Invest Ophthalmol Vis Sci. 2009; 50:2033-9. [PubMed: 19117917]

18. Eye Diseases Prevalence Research Group. Causes and prevalence of visual impairment among adults in the United States. Arch Ophthalmol. 2004; 122:477-85. [PubMed: 15078664]

19. [Accessed August 15, 2010] Summary of Medical Advisory Board Practices in the United States. Jun 18. 2003 Available at: http://www.mdsupport.org/drivingsummary.pdf

20. Moll AC, van der Linden AJ, Hogeweg M, et al. Prevalence of blindness and low vision of people over 30 years in the Wenchi district, Ghana, in relation to eye care programmes. Br J Ophthalmol. 1994; 78:275-9. [PubMed: 8199113]

21. Guzek JP, Anyomi FK, Fiadoyor S, Nyonator F. Prevalence of blindness in people over 40 years in the Volta region of Ghana. Ghana Med J. 2005; 39:55-62. [PubMed: 17299544]

22. Faal H, Minassian D, Sowa S, Foster A. National survey of blindness and low vision in The Gambia: results. Br J Ophthalmol. 1989; 73:82-7. [PubMed: 2784691] 
23. Kortlang C, Koster JC, Coulibaly S, Dubbeldam RP. Prevalence of blindness and visual impairment in the region of Ségou, Mali: a baseline survey for a primary eye care programme. Trop Med Int Health. 1996; 1:314-9. [PubMed: 8673833]

24. Whitworth JA, Gilbert CE, Mabey DM, et al. Visual loss in an onchocerciasis endemic community in Sierra Leone. Br J Ophthalmol. 1993; 77:30-2. [PubMed: 8435395]

25. Wilson MR, Mansour M, Ross-Degnan D, et al. Prevalence and causes of low vision and blindness in the Extreme North Province of Cameroon, West Africa. Ophthalmic Epidemiol. 1996; 3:23-33. [PubMed: 8705870]

26. Tielsch JM, Sommer A, Witt K, et al. Baltimore Eye Survey Research Group. Blindness and visual impairment in an American urban population: the Baltimore Eye Survey. Arch Ophthalmol. 1990; 108:286-90. [PubMed: 2271016]

27. Hyman L, Wu SY, Connell AM, et al. Barbados Eye Study Group. Prevalence and causes of visual impairment in the Barbados Eye Study. Ophthalmology. 2001; 108:1751-6. [PubMed: 11581045]

28. Munoz B, West SK, Rubin GS, et al. SEE Study Team. Causes of blindness and visual impairment in a population of older Americans: the Salisbury Eye Evaluation Study. Arch Ophthalmol. 2000; 118:819-25. [PubMed: 10865321]

29. Varma R, Ying-Lai M, Klein R, et al. Los Angeles Latino Eye Study Group. Prevalence and risk indicators of visual impairment and blindness in Latinos: the Los Angeles Latino Eye Study. Ophthalmology. 2004; 111:1132-40. [PubMed: 15177963]

30. Muñoz B, West SK, Rodriguez J, et al. Blindness, visual impairment and the problem of uncorrected refractive error in a Mexican-American population: Proyecto VER. Invest Ophthalmol Vis Sci. 2002; 43:608-14. [PubMed: 11867574]

31. Klein R, Klein BE, Linton KL, De Mets DL. The Beaver Dam Eye Study: visual acuity. Ophthalmology. 1991; 98:1310-5. [PubMed: 1923372]

32. Attebo K, Mitchell P, Smith W. Visual acuity and the causes of visual loss in Australia: the Blue Mountains Eye Study. Ophthalmology. 1996; 103:357-64. [PubMed: 8600410]

33. Xu L, Wang Y, Li Y, et al. Causes of blindness and visual impairment in urban and rural areas in Beijing: the Beijing Eye Study. Ophthalmology. 2006; 113:1134-41. [PubMed: 16647133]

34. Iwano M, Nomura H, Ando F, et al. Visual acuity in a community-dwelling Japanese population and factors associated with visual impairment. Jpn J Ophthalmol. 2004; 48:37-43. [PubMed: 14767649]

35. Thulasiraj RD, Nirmalan PK, Ramakrishnan R, et al. Blindness and vision impairment in a rural south Indian population: the Aravind Comprehensive Eye Survey. Ophthalmology. 2003; 110:1491-8. [PubMed: 12917162]

36. Taylor HR, Livingston PM, Stanislavsky YL, McCarty CA. Visual impairment in Australia: distance visual acuity, near vision, and visual field findings of the Melbourne Visual Impairment Project. Am J Ophthalmol. 1997; 123:328-37. [PubMed: 9063242]

37. Baasanhu J, Johnson GJ, Burendei G, Minassian DC. Prevalence and causes of blindness and visual impairment in Mongolia: a survey of populations aged 40 years and older. Bull World Health Organ. 1994; 72:771-6. [PubMed: 7955027]

38. Tishkoff SA, Reed FA, Friedlaender FR, et al. The genetic structure and history of Africans and African Americans. Science. 2009; 324:1035-44. [PubMed: 19407144]

39. Campbell MC, Tishkoff SA. African genetic diversity: implications for human demographic history, modern human origins, and complex disease mapping. Annu Rev Genomics Hum Genet. 2008; 9:403-33. [PubMed: 18593304]

40. Kosoko-Lasaki O, Gong G, Haynatzki G, Wilson MR. Race, ethnicitiy and prevalence of primary open-angle glaucoma. J Natl Med Assoc. 2006; 98:1626-9. [PubMed: 17052053]

41. Adeyemo AA, Chen G, Chen Y, Rotimi C. Genetic structure in four West African population groups. BMC Genetics [serial online]. 2005; 6:38. Available at: http://www.biomedcentral.com/ 1471-2156/6/38.

42. Reed FA, Tishkoff SA. African human diversity, origins and migrations. Curr Opin Genet Dev. 2006; 16:597-605. [PubMed: 17056248] 
43. Sikora M, Laayouni $\mathrm{H}$, Calafell F, et al. A genomic analysis identifies a novel component in the genetic structure of sub-Saharan African populations. Eur J Hum Genet. 2011; 19:84-8. [PubMed: 20736976]

44. Bryc K, Auton A, Nelson MR, et al. Genome-wide patterns of population structure and admixture in West Africans and African Americans. Proc Natl Acad Sci U S A. 2010; 107:786-91. [PubMed: 20080753]

45. Rosa A, Ornelas C, Jobling MA, et al. Y-chromosomal diversity in the population of GuineaBissau: a multiethnic perspective. BMC Evol Biol [serial online]. 2007; 7:124. Available at: http:// www.biomedcentral.com/1471-2148/7/124.

46. Scheinfeldt LB, Soi S, Tishkoff SA. Working toward a synthesis of archaeological, linguistic, and genetic data for inferring African population history. Proc Natl Acad Sci U S A. 2010; 107(suppl): 8931-8. [PubMed: 20445100]

47. Campbell MC, Tishkoff SA. The evolution of human genetic and phenotypic variation in Africa. Curr Biol. 2010; 20:R166-73. [PubMed: 20178763]

48. Pizzarello L, Abiose A, Ffytche T, et al. VISION 2020: The Right to Sight: a global initiative to eliminate avoidable blindness. Arch Ophthalmol. 2004; 122:615-20. [PubMed: 15078680]

49. West S, Sommer A. Prevention of blindness and priorities for the future. Bull World Health Organ. 2001; 79:244-8. [PubMed: 11285670]

50. Resnikoff S, Felch W, Gauthier T-M, Spivey B. The number of ophthalmologists in practice and training worldwide: a growing gap despite more than 200000 practitioners. Br J Ophthalmol. Published online March 26, 2012. 10.1136/bjophthalmol-2011-301378 
Table 1

Demographic Characteristics of Subjects in the Tema Eye Survey

\begin{tabular}{|c|c|}
\hline Age $($ Mean \pm SD) & $52.7 \pm 10.9$ years $($ range $40-110)$ \\
\hline Gender & $\begin{array}{l}\text { Male } 39.7 \% \\
\text { Female: } 60.3 \%\end{array}$ \\
\hline Region of Birth ${ }^{*}$ & $\begin{array}{l}\text { Ashanti - } 4.8 \%(20.3 \%) \\
\text { Greater Accra - 29.3\% (17.1\%) } \\
\text { Eastern - } 15.2 \%(10.0 \%) \\
\text { North - } 4.4 \%(9.5 \%) \\
\text { Western - 3.9\% (10.2\%) } \\
\text { Brong Ahafo - 0.6\% (9.5\%) } \\
\text { Volta - } 18.5 \%(8.1 \%) \\
\text { Central - } 14.7 \%(8.1 \%) \\
\text { Upper East - 0.3\% (4.5\%) } \\
\text { Upper West - } 0.2 \%(2.7 \%) \\
\text { Other Countries - } 7.7 \%\end{array}$ \\
\hline Marital Status & $\begin{array}{l}\text { Married - } 66.2 \% \\
\text { Single - } 2.7 \% \\
\text { Divorced - } 11.4 \% \\
\text { Widowed - } 15.5 \% \\
\text { Unknown }-4.2 \%\end{array}$ \\
\hline Previous Eye Examination & $\begin{array}{l}\text { Yes }-37.8 \% \\
\text { No }-61.9 \% \\
\text { Unknown }-0.3 \%\end{array}$ \\
\hline History of Diabetes Mellitus & $\begin{array}{l}\text { Yes }-4.7 \% \\
\text { No- } 33.9 \% \\
\text { Unknown- } 61.4 \%\end{array}$ \\
\hline History of Systemic Hypertension & $\begin{array}{l}\text { Yes }-29.1 \% \\
\text { No }-31.8 \% \\
\text { Unknown }-39.1 \%\end{array}$ \\
\hline History of Eye Disease & $\begin{array}{l}\text { Yes }-29.7 \% \\
\text { No }-70.3 \%\end{array}$ \\
\hline
\end{tabular}

Approximate percentage of people residing in each of Ghana's ten regions in 2006 given in parentheses for comparison. SD - standard deviation 


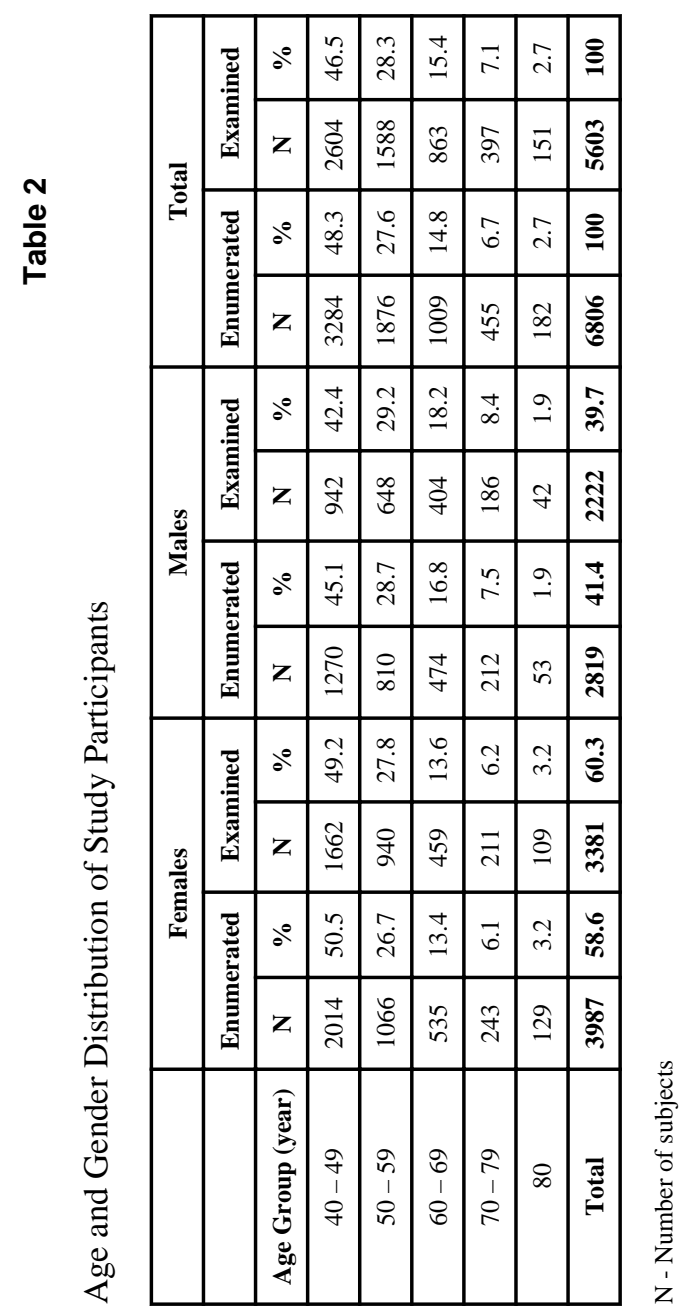

Ophthalmology. Author manuscript; available in PMC 2013 September 01. 


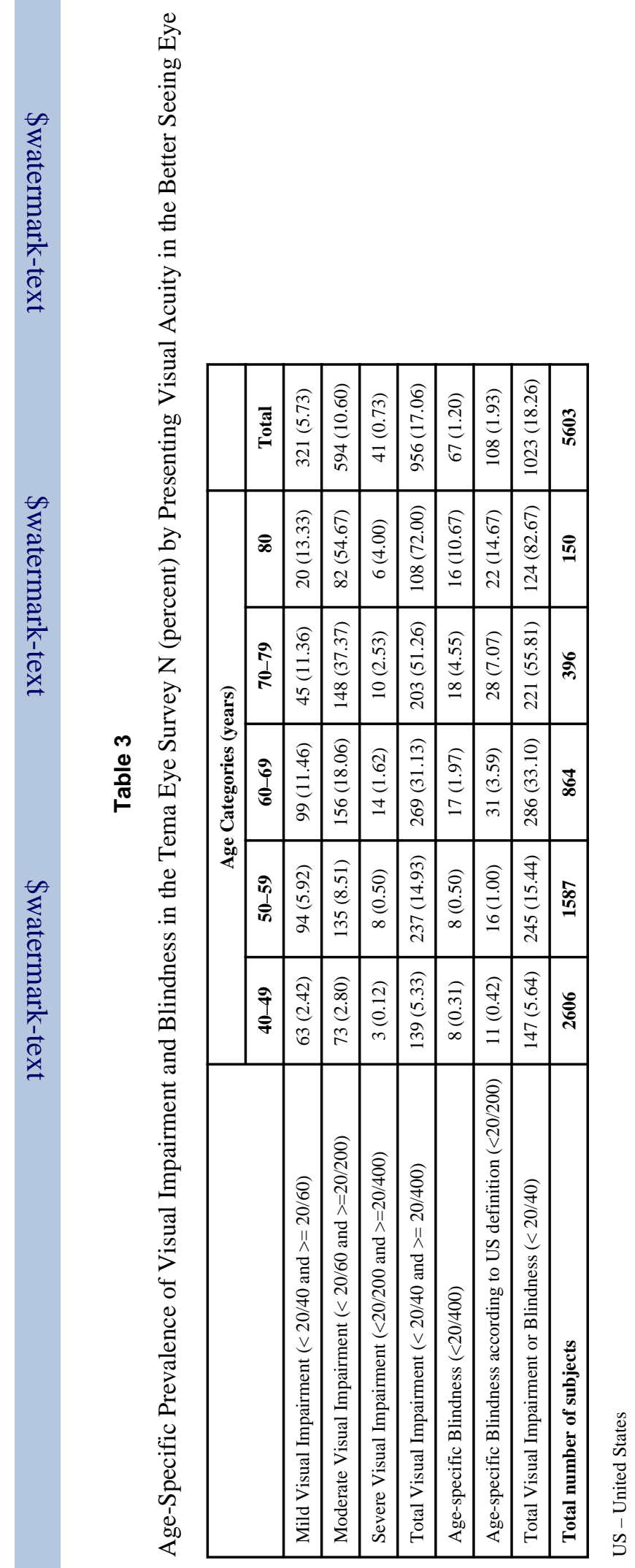

Ophthalmology. Author manuscript; available in PMC 2013 September 01. 


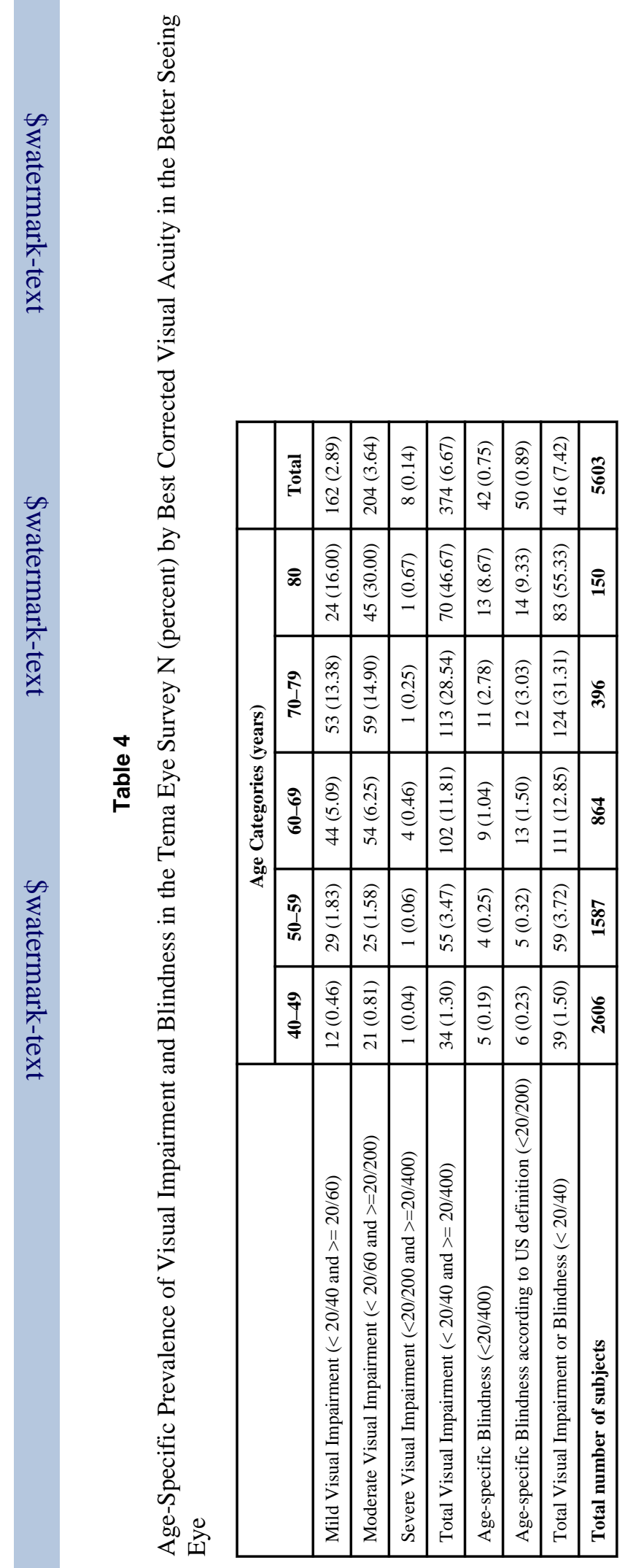

Ophthalmology. Author manuscript; available in PMC 2013 September 01. 


\section{Table 5}

Non-Refractive Causes of Visual Impairment and Blindness in the Tema Eye Survey (Number of subjects and percentages)

\begin{tabular}{|l|c|c|c|}
\hline Etiology & Visual Impairment $^{*}$ & Blindness $^{\dagger}$ & Blindness $^{\ddagger}$ \\
\hline Cataract & $198(53.4 \%)$ & $19(44.2 \%)$ & $20(43.5 \%)$ \\
\hline Glaucoma & $52(14.0 \%)$ & $9(20.9 \%)$ & $10(21.7 \%)$ \\
\hline Corneal Opacification & $28(7.5 \%)$ & $4(9.3 \%)$ & $4(8.7 \%)$ \\
\hline Non glaucomatous Optic Atrophy & $9(2.4 \%)$ & $3(7.0 \%)$ & $3(6.5 \%)$ \\
\hline Retinal disease $\mathcal{S}^{\text {Others }}$ & $26(7.0 \%)$ & $3(7.0 \%)$ & $4(8.7 \%)$ \\
\hline Undetermined/No Show & $14(3.8 \%)$ & 0 & 0 \\
\hline Total & $44(11.9 \%)$ & $5(11.6 \%)$ & $5(10.9 \%)$ \\
\hline
\end{tabular}

*Visual Impairment defined as Best Corrected Visual Acuity $<20 / 40$ but $\geq 20 / 400$ in the better seeing eye

${ }^{\dagger}$ Blindness defined as Best Corrected Visual Acuity $<20 / 400$ in the better seeing eye

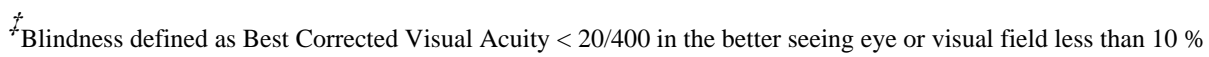

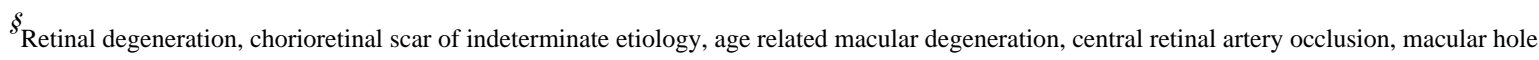


Table 6

Risk Factors for Visual Impairment in the Tema Eye Survey $(\mathrm{N}=371)$

\begin{tabular}{|c|c|c|c|c|}
\hline \multirow{2}{*}{ Risk Indicator } & \multicolumn{2}{|l|}{ Univariate } & \multicolumn{2}{|l|}{ Multivariate } \\
\hline & Odds Ratio (95\% CI) & $P$ value & Odds Ratio (95\% CI) & $P$ value \\
\hline \multicolumn{5}{|l|}{ Age (years) } \\
\hline $40-49$ & Reference & $<0.001$ & Reference & $<0.0001$ \\
\hline $50-59$ & $2.67(1.73-4.12)$ & & $2.53(1.62-3.97)$ & \\
\hline $60-69$ & $10.04(6.75-14.94)$ & & $9.10(6.01-13.80)$ & \\
\hline $70-79$ & $31.37(20.96-46.94)$ & & $28.09(18.33-43.06)$ & \\
\hline 280 & $78.88(49.00-126.98)$ & & 66.58 (39.79-111.39) & \\
\hline Gender & & & & 0.941 \\
\hline Female & Reference & 0.420 & & \\
\hline Male & $0.92(0.74-1.14)$ & & & \\
\hline \multicolumn{5}{|l|}{ Marital Status } \\
\hline Married & Reference & $<0.0001$ & Reference & $<0.0001$ \\
\hline Single & $1.10(1.51-2.39)$ & & $1.97(0.86-4.48)$ & \\
\hline Widowed & $4.79(3.78-6.08)$ & & $1.81(1.38-2.38)$ & \\
\hline Divorced & $1.72(1.22-2.42)$ & & $1.43(0.99-2.07)$ & \\
\hline History of Ocular Disease & $1.28(1.02-1.60)$ & 0.03 & & 0.1 \\
\hline \multicolumn{5}{|l|}{ History of Hypertension } \\
\hline No & Reference & $<0.0001$ & & 0.06 \\
\hline Yes & $2.42(1.82-3.23)$ & & & \\
\hline Unknown & $1.71(1.28-2.30)$ & & & \\
\hline \multicolumn{5}{|l|}{ History of Diabetes } \\
\hline No & Reference & $<0.01$ & & 0.32 \\
\hline Yes & $2.14(1.38-3.31)$ & & & \\
\hline Unknown & $1.26(1.00-1.61)$ & & & \\
\hline
\end{tabular}

$\mathrm{N}$ - Number of Subjects; CI - Confidence Interval 
Table 7

Risk Factors for Blindness in the Tema Eye Survey $(\mathrm{N}=46)$

\begin{tabular}{|c|c|c|c|c|}
\hline \multirow{2}{*}{ Risk Indicator } & \multicolumn{2}{|l|}{ Univariate } & \multicolumn{2}{|l|}{ Multivariate } \\
\hline & Odds Ratio (95\% CI) & $P$ value & Odds Ratio (95\% CI) & P value \\
\hline \multicolumn{5}{|l|}{ Age (years) } \\
\hline $40-49$ & Reference & $<0.001$ & Reference & $<0.0001$ \\
\hline $50-59$ & $1.64(0.48-5.67)$ & & $1.66(0.48-5.7)$ & \\
\hline $60-69$ & $7.32(2.57-20.86)$ & & $6.68(2.31-19.29)$ & \\
\hline $70-79$ & $14.86(5.14-43.01)$ & & $14.66(5.06-42.49)$ & \\
\hline 280 & $49.36(17.35-140.44)$ & & $43.68(15.10-126.32)$ & \\
\hline \multicolumn{5}{|l|}{ Gender } \\
\hline Female & Reference & 0.70 & & 0.90 \\
\hline Male & $0.89(0.49-1.62)$ & & & \\
\hline \multicolumn{5}{|l|}{ Marital Status } \\
\hline Married & Reference & $<0.0001$ & & 0.106 \\
\hline Single & $2.73(0.63-11.88)$ & & & \\
\hline Widowed & $3.84(1.95-7.56)$ & & & \\
\hline Divorced & $2.59(1.12-5.98)$ & & & \\
\hline History of Ocular Disease & $1.28(1.02-1.60)$ & 0.03 & $2.76(1.50-5.07)$ & 0.001 \\
\hline \multicolumn{5}{|l|}{ History of Hypertension } \\
\hline No & Reference & 0.22 & & 0.1 \\
\hline Yes & & & & \\
\hline Unknown & & & & \\
\hline \multicolumn{5}{|l|}{ History of Diabetes } \\
\hline No & Reference & 0.77 & & 0.81 \\
\hline Yes & $1.42(0.41-4.92)$ & & & \\
\hline Unknown & $0.92(0.49-1.73)$ & & & \\
\hline
\end{tabular}

$\mathrm{N}$ - Number of Subjects; CI - Confidence Interval 